\title{
Diverticulosis yeyunal perforada: una causa infrecuente de abdomen agudo
}

\author{
Perforated jejunal diverticulosis: a rare cause of acute abdomen
}

Andrés Montaner Sanchis ${ }^{1}$, Alejandra De Andrés Gómez ${ }^{1}$, Antonio Melero Abellán ${ }^{1}$ y Germán Eleuterio Cerveró ${ }^{1}$

Mujer de 78 años con antecedentes de diverticulitis colónica que consulta por dolor abdominal de 48 horas de evolución. A la exploración física presenta irritación peritoneal difusa. Analíticamente destacan leucocitosis de 18.400 células $/ \mathrm{mm}^{3}$ con neutrofilia y proteína $\mathrm{C}$ reactiva de $36,8 \mathrm{mg} / \mathrm{dL}$.

La tomografía axial computarizada (TC) muestra edematización de la grasa mesentérica y burbujas de aire intraperitoneales sugestivas de perforación de intestino delgado (Figura 1).

Se realiza una laparotomía exploradora encontrando una peritonitis fibrinopurulenta e intestino delgado repleto de divertículos. El yeyuno proximal presenta un plastrón que contiene una perforación diverticular (Figura 2). Se lleva a cabo un cierre simple mediante sutura con puntos sueltos y lavados de la cavidad abdominal. La paciente evoluciona favorablemente siendo dada de alta al $7^{\circ}$ día.

Los divertículos yeyunales constituyen el 1 a $2 \%$ de toda la enfermedad diverticular. Son más frecuentes en adultos mayores y suelen asociarse a divertículos colónicos ${ }^{1}$. Usualmente son asintomáticos, aunque en un 10-20\% de los casos pueden surgir complicaciones ${ }^{2}$.
Hospital General Universitario de Valencia Valencia, España.

Recibido 2021-03-09, aceptado 2021-03-16

Correspondencia a: Dr. Andrés Montaner Sanchis andres92.ms@gmail.com

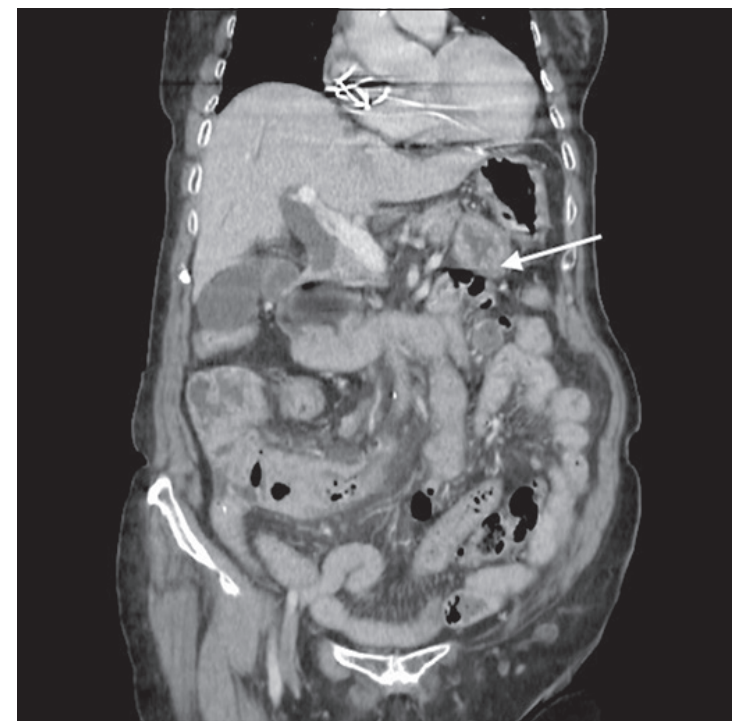

Figura 1. Corte coronal de TC donde se visualiza edematización de la grasa mesentérica y burbujas de aire intraperitoneales sugestivas de perforación de intestino delgado.

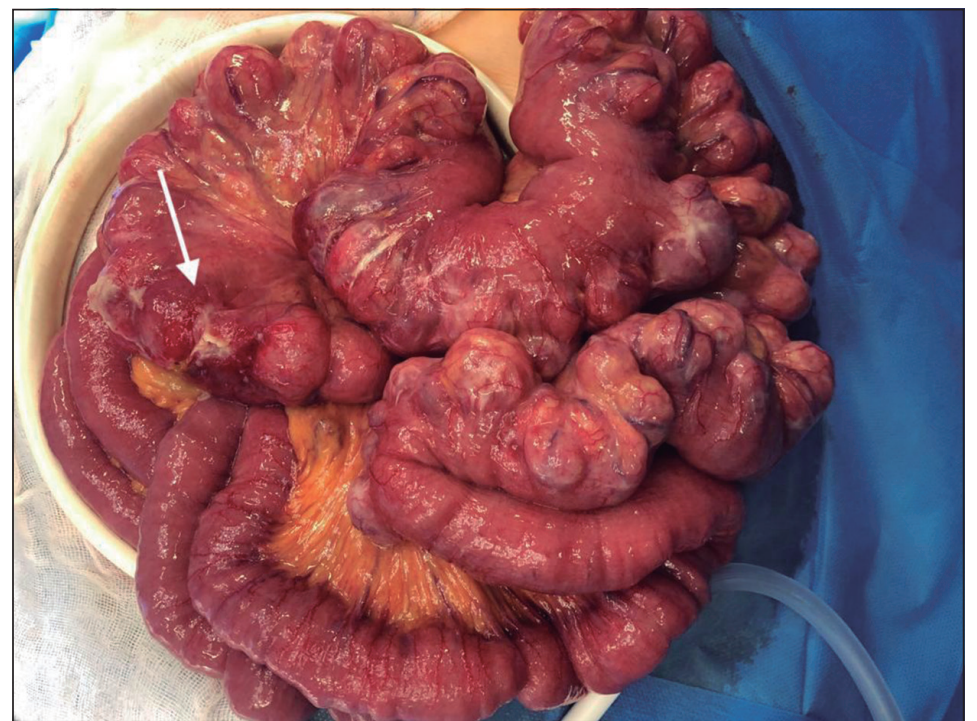

Figura 2. Intestino delgado desplegado y repleto de divertículos con perforación de uno de ellos a nivel de yeyuno proximal. 


\section{Responsabilidades éticas}

Protección de personas y animales. Los autores declaran que para esta investigación no se han realizado experimentos en seres humanos ni en animales.
Confidencialidad de los datos. Los autores declaran que en este artículo no aparecen datos de pacientes.

Conflictos de interés: no hay.

\section{Bibliografía}

1. Palder SB, Frey CB. Jejunal Diverticulosis. Arch Surg.
1988;123:889-94. doi: 10.1001/ archsurg.1988.01400310103018

2. Motos J, Velasco FJ, Ferrer M,

Ferrer M, Rosado R. Abdomen agudo secundario a diverticulitis yeyunal perforada. Gastroenterol Hepatol. 2014;37:467-8. doi: 10.1016/j. gastrohep.2013.11.012 